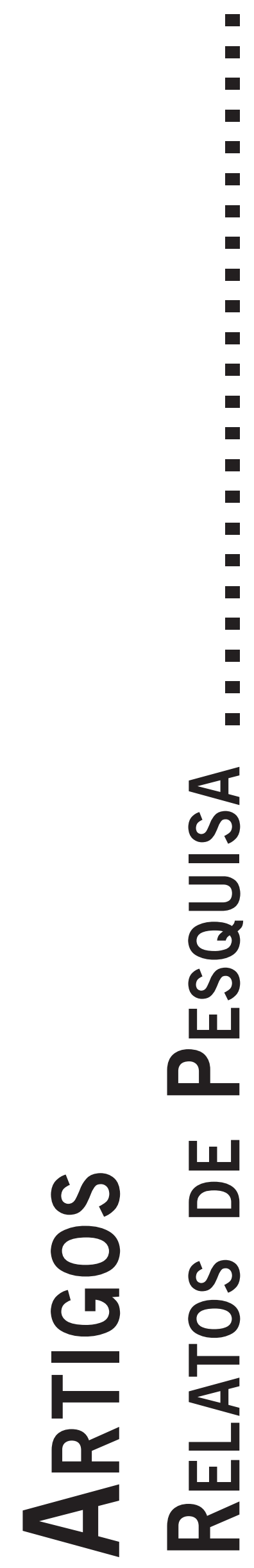




\title{
O Desejo de Ser Mãe e a Barreira da Infertilidade: Uma Compreensão Fenomenologica
}

\author{
The Desire to be Mother and the Barrier of Infertility: A Phenomenological Understanding \\ El Deseo de Ser Madre y la Barrera de la Infertilidad: Una Comprensión Fenomenológica
}

Renata Ramalho Queiroz Leite

Ana Maria Monte Coelho Frota

\begin{abstract}
Resumo: Abalando o projeto parental de muitos casais, a infertilidade afeta distintas dimensões da vida do sujeito. Tal situação é mais peculiar à mulher, por não corresponder às expectativas de um mundo predominantemente fértil. O presente estudo buscou compreender de que forma a infertilidade afeta a vida e a autoimagem feminina de mulheres com problema de infertilidade que passaram por um tratamento de fertilização in vitro, procurando identificar os significados que elas atribuem à maternidade e à feminilidade. A fenomenologia heideggeriana foi adotada como suporte teórico e metodológico. Por meio de narrativas, foi realizada uma escuta fenomenológica de quatro mulheres em momentos existenciais distintos do tratamento de fertilização in vitro. Pode-se perceber que, ao mesmo tempo em que gera grandes esperanças, possibilitando a conquista da desejada gravidez, o tratamento mobiliza fortes reações emocionais.
\end{abstract}

Palavras-chave: Infertilidade; Maternidade; Fertilização in vitro; Método fenomenológico.

Abstract: Shaking the parental project of many couples, infertility affects several dimensions of the subject life. This situation is more peculiar to women, for not coresponde the expectations of a world predominantly fertile. This study sought to understand how infertility affects the life and female self-image of women with infertility problem which went through a treatment of in vitro fertilization, seeking to identify the meanings they attach to maternity and femininity. The heideggeriana phenomenology was adopted as theoretical and methodological support for this study. Through semi-structured interview, was done a phenomenological listening of four women who were at different existential moments in relation to cycle of in vitro fertilization treatment. It's possible to realize that at the same time it creates great expectations, making possible the achievement of desired pregnancy, the treatment mobilizes strong emotional reactions.

Keywords: Infertility; Maternity; In vitro fertilization; Phenomenological method.

Resumen: Dificultando el proyecto parental de muchas parejas, la infertilidad genera efectos en distintas dimensiones de la vida del sujeto. Tal situación es más ínsita a la mujer, por no corresponder a las expectativas de un mundo predominantemente fecundo. El presente estudio ha buscado comprender de qué forma la infertilidad afecta la vida y la imagen que las mujeres tienen de sí propias, cuando sufren problemas de infertilidad y deciden someterse a un procedimiento de fecundación in vitro. Particularmente, tratamos de identificar los significados que ellas atribuyen a la maternidad y a la feminidad. La fenomenología heideggeriana fue adoptada como suporte teórico y metodológico. Por medio de narraciones, fue realizada una "escucha" fenomenológica de cuatro mujeres en diferentes momentos existenciales del procedimiento de fecundación in vitro. Puede ser percibido que, al mismo tiempo en que son generadas grandes esperanzas, posibilitando la conquista del muy deseado embarazo, el tratamiento moviliza fuertes reacciones emocionales.

Palabras clave: Infertilidad; Maternidad; Fertilización in vitro; Método fenomenológico.

\section{Introdução}

Cada vez mais recorrente em nossa sociedade, a infertilidade é um problema que afeta o bem-estar psíquico e emocional do indivíduo. Gerar um filho traz um significado pessoal muito importante para a mulher, uma vez que a gravidez pode representar a confirmação de sua feminilidade. Assim sendo, a infertilidade pode ferir e desestruturar a representação da autoimagem feminina, uma vez que costuma afetar a maneira como as mulheres se sentem a respeito de si mesmas. Imersos em uma grande instabilidade emocional, os casais inférteis procuram as clínicas de reprodução humana na esperança de terem um filho biológico. A fertilização in vitro é uma das técnicas de reprodução assistida e caracteriza-se por produzir embriões em contexto laboratorial.

O presente estudo buscou compreender como a infertilidade afeta a vida e a autoimagem feminina de mulheres que estão passando, ou que já passaram, por um tratamento de fertilização in vitro, procurando perceber, os significados que essas mulheres atribuem à maternidade e ao "ser mulher". 


\section{A barreira da infertilidade}

A limitação imposta pela infertilidade aos casais que se deparam com o impedimento de dar continuidade à própria existência, através de um filho biológico, envolve elementos de ordem biológica e psíquica. Por mais que a infertilidade deva ser considerada como um problema do casal, a mulher parece ser vista como a principal responsável pelos problemas reprodutivos, não só culturalmente, como também dentro da comunidade médica. Borlot \& Trindade (2004) constataram que, por mais que este não seja o procedimento padrão recomendado, os exames para investigar o motivo da infertilidade ainda são indicados primeiramente às mulheres. Do mesmo modo, pensam Modelli \& Levy (2006):

Apesar de cada vez mais falarmos que o casal é a figura envolvida neste tratamento, é para a mulher que as atenções são dispensadas, com uma grande demanda de avaliações. Ao homem, cabe executar exames simples de espermograma para poder suspender a possibilidade de ozoospermia, ou baixa qualidade de esperma. Caso este exame resulte normal, fica o homem isento de qualquer 'responsabilidade' que justifique a dificuldade de engravidar. Cabe uma busca mais pormenorizada na mulher, mediante exames invasivos. (p. 52)

Além disso, a concepção de infertilidade, ainda hoje, coloca a mulher numa posição estigmatizante. Ao mesmo tempo em que gera grandes esperanças, por poder possibilitar a conquista da desejada gravidez, o tratamento de reprodução assistida mobiliza fortes reações emocionais, podendo ser sentida como uma "experiência devastadora” (Borlot \& Trindade, 2004).

Na medida em que estão profundamente envolvidos com o desejo da maternidade e paternidade, os casais inférteis também entram em contato com questões relacionadas aos seus referenciais de masculinidade e feminilidade. Sentem-se feridos no seu orgulho de ser homem e de ser mulher quando amputados de sua função reprodutiva. De um modo geral, uma vez que o desejo de maternidade e paternidade se relaciona intimamente com as vivências particulares de cada sujeito, a experiência emocional da infertilidade possui, da mesma forma, um caráter eminentemente singular, uma vez que, segundo Trindade \& Enumo (2002), a angústia decorrente do diagnóstico de infertilidade pode variar de acordo com a valorização atribuída à maternidade e à paternidade.

Tanto o diagnóstico de infertilidade quanto o tratamento de reprodução assistida geram muitos sentimentos conflitantes no casal e, em especial, na mulher. Diante da perda do controle sobre si, seu corpo e seu projeto de vida, a mulher infértil depara-se com uma sensação de tristeza, de incompletude, de solidão e de inferioridade.
Percebendo que a realização do seu desejo não está em seu poder, é comum se sentirem impotentes, fracassadas, deficientes, humilhadas, desamparadas e injustiçadas, apresentando sinais de depressão, inquietude e desânimo (Oliveira, 2006). Assim, capaz de ocasionar uma queda na autoestima feminina, a infertilidade é, muitas vezes, sentida como um defeito, provocando um sentimento de desvalorização e afetando outras esferas da vida. Devido a essa sensação de "anormalidade", as mulheres com problema de infertilidade costumam ficar com vergonha perante a sociedade, uma vez que, geralmente, são responsabilizadas pelo sucesso ou pelo fracasso da reprodução.

O processo de reprodução assistida é vivenciado em meio a uma grande instabilidade emocional, marcada por sentimentos extremos de esperança e desilusão, sendo comum aparecer um estado de disforia, que se caracteriza por um misto de ansiedade e depressão. Os sentimentos de tristeza e depressão são os mais comuns em pacientes inférteis, estando eles relacionados com perdas, desilusão, lamentações e desesperança. A raiva e a frustração vêm acompanhadas de irritabilidade, agressividade, ressentimento e mágoa. Além disso, há uma forte sensação de culpa, inclusive pelos erros do passado, havendo a impressão de estar decepcionando as pessoas e de estar sendo castigada ou punida através da infertilidade. O choque e a negação costumam ocorrer especialmente na fase do diagnóstico, tendendo a desaparecer no decorrer do tratamento. Já a ansiedade, a preocupação e o desespero aparecem como fenômenos cíclicos ao longo do tratamento, vindo acompanhados de choro fácil, distúrbios de sono, lapsos de memória, dificuldade de relaxar e oscilação de humor (Melamed, Ribeiro \& Seger-Jacob, 2006).

Além de provocar efeitos devastadores no âmbito pessoal e conjugal, a condição de infértil pode também desestabilizar as relações do indivíduo com seu entorno social, uma vez que o casal infértil se percebe na impossibilidade de cumprir a função parental esperada pela sociedade. Essa cobrança gera dificuldades e incômodo nos casais para lidar com seu grupo social, sendo necessário enfrentar a influência da família, dos amigos e da religião, que estimulam o desejo de ter filho (Weiss, 2006).

Pensar a respeito da reprodução assistida nos remete, ainda, ao estudo das várias representações sociais de um filho biológico e de como essas diversas significações afetam o desejo dos casais em gerar um filho. Geralmente, o filho biológico é socialmente representado como uma extensão de seus pais, garantindo a manutenção da cadeia de gerações da família. Nesse sentido, é comum que o ser humano busque no filho biológico uma possibilidade de transcendência, uma vez que ele é percebido como uma maneira de perpetuação da própria existência. 


\section{Ser mãe e ser mulher}

Através da maternidade, a mulher passou a ocupar um lugar fundamental na estrutura familiar burguesa, sendo considerada como um elemento agregador necessário para a sobrevivência da família. A maternidade e o cuidado com a administração do lar se configuraram, assim, como funções femininas valorizadas socialmente, permitindo que a mulher fosse reconhecida e ocupasse uma posição de aparente prestígio dentro da sociedade. De acordo com o pensamento moderno, a mulher era biologicamente pré-determinada a gestar e a cuidar dos filhos. Deste modo, era por meio da maternidade que ela realizava seu destino fisiológico e sua vocação "natural". Através da amamentação, da higiene, do cuidado e da presença materna constante, a mulher-mãe provava o seu amor e ganhava visibilidade como identidade característica do feminino.

Historicamente, a maternidade foi construída como o ideal máximo da mulher, representando um caminho para alcançar a plenitude e a realização da feminilidade, atrelado a um sentido de abnegação e sacrifícios prazerosos. Nas últimas décadas do século XVIII, e principalmente no século XIX, as mulheres assumiram o papel da boa mãe, com dedicação integral aos filhos e responsabilidade pelo espaço privado da família. Surge, assim, a representação social de devotamento e sacrifício inerente à maternidade, que passa a ser vista como um sofrimento voluntário e indispensável para a mulher (Badinter, 1985; Borsa \& Feil, 2008; Trindade \& Enumo, 2002). Contudo, o aparecimento dos métodos contraceptivos, a possibilidade de aborto, a entrada da mulher no mercado de trabalho com a consequente inserção social feminina, o divórcio e a chance de estabelecer novas relações amorosas contribuíram para o declínio do tradicional modelo familiar, com alterações significativas na vida pública e privada. Nesse contexto, aconteceu uma espécie de reinvenção do feminino, permitindo que a mulher assumisse novos papéis e novos desafios, uma vez que conquistou o espaço profissional, devendo conciliar, então, esta nova função com suas antigas atribuições. Desta maneira, podemos perceber que a estrutura familiar sofreu mudanças significativas com o passar dos tempos. Nos dias de hoje, muitas mulheres trabalham fora de casa, procuram a realização profissional e contribuem com a renda familiar.

Apesar dos novos papéis que vem ocupando na sociedade contemporânea, a imagem associada à mulher-mãe ainda é muito valorizada e a maternidade continua sendo idealizada e compreendida como um salto qualitativo para a vida da mulher, afirmam Barbosa \& RochaCoutinho (2007). A gravidez não é, de fato, a única maneira de realização da feminilidade. Contudo, como apenas a mulher pode engravidar, a maternidade representa um traço absoluto que marca a diferença de gênero. Talvez essa diferença contribua para a ideia de que um filho significa a confirmação da feminilidade, esperado pelas próprias mulheres, pelos parceiros e pelo entorno familiar e social. Como bem defendem Braga \& Amazonas (2005, p. 18): "O feminino não se traduz na maternidade, o desejo pelo filho não é inelutável ou imprescindível. A maternidade se configura nessa fronteira complexa entre natureza e cultura, entre força impulsionadora e construção permanente". Porém, percebemos que nem sempre é o que acontece, como veremos na fala de nossas colaboradoras neste estudo.

Desde muito novas as mulheres são socialmente convencidas de que ser mãe é necessário para se sentirem completas e realizadas, cabendo a elas a responsabilidade pelo sucesso dessa função. Nesse contexto, a maternidade ainda é, culturalmente, naturalizada, tanto como destino biológico, quanto como valor social inerente à consolidação da identidade feminina. Pelo fato de assuntos relacionados às crianças e concepção fazerem parte do universo feminino, quando há problema de infertilidade, geralmente, a responsabilidade recai sobre as mulheres. Além disso, raramente os estudos históricos e antropológicos fazem referência à infertilidade masculina. Assim, em meio à naturalização do valor social da maternidade, muitas vezes essas mulheres se sentem culpadas e inferiores devido à impossibilidade de cumprir a função parental tão esperada e cobrada pela sociedade. Diante dessa imposição social da maternidade para a "mulher normal", a mulher com problema de infertilidade se sente menos feminina e, consequentemente, menos atraente. É nesse sentido que Seger-Jacob (2006) considera que a infertilidade é percebida pela mulher como uma ameaça à sua identidade feminina.

A reprodução assistida fornece, então, um campo privilegiado em possibilidades de articulação entre o feminino e o desejo de gerar um filho, uma vez que as mulheres com dificuldade para engravidar estão em constante contato com esse desejo.

\section{Metodologia}

Pretendendo compreender e refletir acerca do fenômeno da infertilidade e de como ele afeta a vida e a autoimagem feminina de mulheres que estão passando por um tratamento de fertilização in vitro, utilizamos a metodologia qualitativa para realização dessa pesquisa. Tal abordagem "pretende conhecer, esclarecer, entender e interpretar os processos que constituem os fenômenos objetos de investigação" (Ozella, 2003; p. 122). Além disso, fizemos uso do enfoque fenomenológico, por acreditar que este seria o método mais adequado para alcançar os objetivos desta pesquisa. A fenomenologia enfatiza a particularidade do ser e a dimensão existencial do viver, buscando compreender os sentidos e significados que 0 sujeito atribui à sua vivência no seu contato com o mundo (Frota, 2001; Dutra, 2002). 
A fenomenologia nasceu no final do século XIX, negando a existência de uma verdade absoluta e acreditando que os fenômenos observados são uma representação do real. Deste modo, essa perspectiva metodológica surgiu rompendo com o modelo de ciência cartesiano e metafísico, que afirma a existência de uma verdade universal e imutável, de um conhecimento científico puro e absoluto, capaz de ser apreendido pelo uso da razão.

A Fenomenologia Transcendental de Husserl e a Hermenêutica Ontológica de Heidegger são consideradas os principais pilares do pensamento fenomenológico. Por não acreditar na possibilidade da redução fenomenológica como sugerida por Husserl, acabamos por adotar Heidegger e sua hermenêutica como instrumento metodológico desta pesquisa. Caracterizada por sua fidelidade radical à ontologia, a concepção heideggeriana defende que a realidade se desvela na própria existência. Heidegger "quer entender a vida e seus fenômenos desde si mesmo, quer participar e não suspender o próprio viver" (Frota, 2001; p. 12). Pretendemos, enfim, compreender a experiência de mulheres que vivem ou já viveram o tratamento de inseminação in vitro. Vale ressaltar que o termo experiência é aqui compreendido de acordo com o sentido dado por Rogers \& Kinget (1975). De acordo com esta mesma compreensão, para Dutra (2002), a experiência é uma dimensão existencial do vivido, dado que ela nos remete a tudo o que foi aprendido, experimentado e vivido pelo sujeito. Deste modo, achamos que compreender a experiência das colaboradoras é acessar a dimensão existencial do vivido, dado que ela nos remete ao que foi vivido, experimentado e aprendido por elas. As narrativas foram, então, os instrumentos escolhidos para abordar, nos aproximar e compreender as experiências.

Na medida em que é narrada, a experiência é re-significada e re-vivida pelo sujeito no presente. Portanto, a narrativa não se restringe ao relato de uma experiência vivida e que já acabou. Ela se reconstrói e se re-configura no momento em que é relatada. Aquele que narra sua experiência, conta com a presença do ouvinte, o qual, por sua vez, ao contar aquilo que ouviu, torna-se também um narrador. A relação estabelecida na narrativa é uma relação de intersubjetividade. Como bem discute Frota (2001): "Toda narrativa traz consigo a comunicação de um sentido, mas na relação com o outro. O sentido de uma narrativa, portanto, se amalgama à própria existência de quem a escuta, se entrelaça com a história de quem a escuta e, posteriormente, a narra” (p. 17). Para Melo (2012), o psicólogo clínico pesquisador deve intervir na realidade pela via do sentido, "construindo a retomada da autonomia subjetiva dos participantes e cumprindo seu papel de agente de transformação de realidades sociais” (p. 90). Também Holanda (2001) salienta que nas pesquisas de cunho fenomenológico, os pesquisadores não prescindem da sua participação no ato de pesquisa sendo, mesmo, um co-pesquisador.
O contato com as nossas colaboradoras aconteceu por meio de uma clínica de reprodução assistida localizada em Fortaleza (Ceará), que selecionou e indicou pacientes para participarem desta pesquisa. Na tentativa de identificar possíveis variações e singularidades no relato de mulheres que se encontram em diferentes momentos do tratamento, as quatro colaboradoras foram selecionadas de acordo com os seguintes critérios: (1) uma mulher que está começando o tratamento de fertilização pela primeira vez - Carla; (2) uma mulher que já fez fertilização in vitro, não engravidou e pretende tentar o tratamento novamente - Rebeca; (3) uma mulher que já fez fertilização in vitro, não engravidou e desistiu de tentar o tratamento mais uma vez - Amanda; (4) uma mulher que fez fertilização e está grávida - Joana. Vale ressaltar que a identidade das colaboradoras, bem como de todos os sujeitos citados por elas, foi mantida em sigilo através da atribuição de nomes fictícios.

Selecionada a amostra, realizamos uma entrevista semiestruturada, visto que essa modalidade deixa o sujeito mais livre para narrar sua experiência vivida. Para tanto, utilizamos três perguntas disparadoras: Como você está vivenciando (vivenciou) o tratamento de fertilização in vitro? Para você, o que significa ser mulher? Como você compreende a maternidade? Além disso, durante a entrevista, nos momentos em que sentimos necessidade, levantamos outras questões que nos instigaram e que consideramos importantes para um melhor esclarecimento e compreensão da experiência relatada.

Não fizemos uso de categorias a priori para interpretação e análise dos dados. Ao contrário, os dados foram interpretados e compreendidos a partir dos conteúdos das narrativas (Frota, 2001, Melo, 2012). Desta forma, não analisamos as narrativas guiadas somente por possíveis categorias presentes nas perguntas geradoras. Nosso olhar transpôs este tipo de análise classificatória, uma vez que todo o material foi analisado a partir do conteúdo emergido nas narrativas.

As entrevistas foram gravadas, transcritas e textualizadas. Pinheiro (2007) descreve o procedimento da textualização das narrativas, ressaltando que esta técnica tem como objetivo aproximar o leitor do mundo experiencial do narrador. Após a textualização das narrativas, as colaboradoras puderam ter acesso ao seu material, podendo complementar, corrigir, modificar, o que julgassem pertinentes. Ao ler as narrativas transcritas e corrigidas pelas colaboradoras, procuramos analisá-las percebendo os conteúdos relevantes a serem discutidos. A partir daí, fizemos as interlocuções necessárias entre o que os autores teorizam e o relato das experiências, procurando promover o encontro entre teoria e vivência. Optamos por analisar cada narrativa individualmente, como forma de preservar um espaço para considerações singulares decorrentes do relato de cada sujeito.

Buscamos compreender como a infertilidade afeta a autoimagem feminina a partir das narrativas, nos apro- 
ximando do fenômeno investigado com todos nossos preconceitos, compreendendo-o a partir de nossas próprias reflexões. A intenção, aqui, foi a de permitir que as narrativas nos atravessassem e nos afetassem, além de garantir um espaço para nos colocarmos enquanto pesquisadoras.

\section{Compreendendo histórias}

\subsection{A história de Carla: uma ansiosa espera}

Carla, 35 anos, há mais de três vem procurando uma solução para o seu problema de infertilidade. Após a realização de uma investigação médica descobriu que, também seu marido, tem um problema de infertilidade, ainda mais grave do que o dela. Contudo, para ela, isso tornou a situação mais difícil, devido ao forte pensamento machista da nossa sociedade, ao relacionar masculinidade e paternidade. Em relação a essa questão, Melamed, Ribeiro \& Seger-Jacob (2006) ressaltam que a infertilidade de causa masculina é, socialmente, vista como baixa virilidade e masculinidade, uma vez que o homem está incapacitado de engravidar uma mulher.

Receber o diagnóstico de infertilidade foi, para Carla, uma experiência bastante difícil, especialmente porque a incapacidade de conceber naturalmente estava no seu esposo. Diante da dor e da fragilidade do marido, sofreu duplamente, chegando a desejar que a dificuldade estivesse somente nela. Tal comportamento assumido por Carla corrobora com os estudos referidos acima, nos quais se afirma que muitas mulheres se sentem responsáveis pelo sofrimento dos maridos, quando existe uma infertilidade no casal. Em sua pesquisa, Borlot \& Trindade (2004) haviam constatado que a infertilidade era vivenciada como "experiência devastadora”, especialmente para as mulheres. Podemos observar isso, claramente, no caso de Carla: "[...] despencou um muro por cima de você. Porque eu me vi logo numa situação: "Eu não vou ser mãe!".

Legitimando a afirmação de Carvalho, Santos, Cressoni-Gomes \& Mazzotti (2006) de que a infertilidade pode prejudicar setores da vida do sujeito, inclusive a relação conjugal, Carla ressalta que a infertilidade atrapalha até mesmo o relacionamento, enfatizando que o casamento precisa ter uma base muito sólida para que o processo seja enfrentado sem desestruturar a relação. Entretanto, a vivência do problema da infertilidade possibilitou que Carla e seu marido ficassem mais unidos e mais cúmplices. Na verdade, Borlot \& Trindade (2004) já haviam observado que muitos casais inférteis acabam se aproximando diante da experiência da infertilidade, confirmando a experiência de Carla.

Carla representa a gestação de um filho biológico como um milagre divino. A sacralização da maternidade pode ser observada nos estudos de Rocha-Coutinho (1994). A autora destaca que é a maternidade que transforma Eva em Maria. Em outras palavras, é a maternidade que transforma a mulher em um ser generoso, subli- me e divino. A respeito dessa questão, Badinter (1985) enfatiza, ainda, que, historicamente, a representação da maternidade foi sendo construída como a atividade mais invejável e mais doce que uma mulher pode vivenciar. Ressaltamos aqui, que para Rocha-Coutinho (1994), é a maternagem de um filho biológico que mais oferece à mulher o status de sacralização.

Diante da infertilidade, Carla, muitas vezes, se sentiu incapaz, especialmente diante de alguma circunstância que revelasse sua falta, sua incompletude. A infertilidade gera, portanto, um sentimento de inutilidade feminina, como se a mulher não fosse mulher suficiente para ser mãe. Podemos perceber isso, claramente, na seguinte fala: "[...] a gente se sente como se fosse uma coisa até inútil, sei lá, não tão mulher. Porque a maternidade é você se sentir mais mulher". Nesse sentido, um filho significa a confirmação de ser mulher e feminina, fato que é ressaltado nos estudos de Carvalho, Seibel, Makuch \& Maluf (2006a). Além disso, podemos compreender que a falta de um filho faz desabrochar a sensação de incompletude em Carla, quando ela afirma: "A mulher só se completa quando ela é mãe". A sensação de Carla é afirmada pelo estudo de Trindade \& Enumo (2002), por exemplo, que constataram que mulheres com problemas de infertilidade costumam se sentir tristes e incompletas, considerando que a realização feminina passaria pela glória de ser mãe.

Carla considera que se a mulher desiste de todas as possibilidades de ter um filho, desconsiderando, inclusive, a fertilização in vitro e a adoção, ela nunca irá se aceitar e poderá passar por uma grande depressão. É como se a maternidade fosse, para ela, uma condição sine qua non para a felicidade feminina. Tal pensamento corrobora com a fala de Makuch (2006), de que, diante de uma sociedade predominantemente fértil, a mulher com problema de infertilidade sente-se inadequada, pois não vivencia os privilégios que a maioria das outras mulheres da sua idade vivencia. Diante da impossibilidade de uma gravidez natural, Carla chegou a pensar em adotar. Entretanto, ela e seu marido decidiram não investir na adoção, pois não saberiam a origem daquela criança, já que ela não seria um "filho de sangue". Parece-nos que a adoção se apresenta como uma possibilidade de viver a maternidade. Porém, esta escolha é, ainda, uma possibilidade remota, para ser pensada somente quando se esgotarem as tentativas da fertilização in vitro.

\subsection{A história de Rebeca: quando o desejo foge do controle}

Rebeca tem quarenta anos e já passou por duas fertilizações in vitro, sem sucesso. Já é mãe de três filhos. Aos dezenove anos, após o nascimento do seu terceiro filho, decidiu ligar as trompas. Diferente do que imaginava, acabou se separando e casando novamente. Deseja 
ter um filho com o novo marido, mas não pode engravidar naturalmente. Mesmo já sendo mãe, Rebeca relatou que receber o resultado negativo das duas fertilizações in vitro sem sucesso, foi uma experiência horrível e muito dolorosa. Tal situação fez com que se deparasse com um forte sentimento de impotência, percebendo que não pode fazer nada para mudar sua condição: "Por mais que eu tente, eu posso tentar uma vez, duas, três, quatro, dez, mas não é uma coisa que eu possa dizer: 'Ah... Agora vai dar certo!'. Não. Então, a gente se sente impotente e ao mesmo tempo super arrependida, porque a laqueadura fui eu que decidi".

Em decorrência de sua escolha, Rebeca assume, em forma de culpa, a responsabilidade por não estar conseguindo engravidar. Cunha, Wanderley e Garrafa (2007) observaram que, quanto mais jovem a mulher se submete à ligadura tubária, maiores são as possibilidades de arrependimento, o que contribui para o aumento da demanda em serviços de reprodução assistida. Apesar de não ter obtido sucesso no resultado final, Rebeca respondeu muito bem ao tratamento nas duas vezes em que o fez. Tal fato intensificou a frustração e decepção diante do resultado negativo: "O processo não é ruim. [...] O processo foi maravilhoso. O ruim mesmo foi só a notícia”.

Apesar dos dois resultados negativos terem sido vivenciados como uma experiência devastadora, a maneira como Rebeca recebeu o resultado da segunda fertilização diferiu um pouco de como ela recebeu o da primeira. Melamed (2006) verificou que a vivência de pelo menos um procedimento de reprodução assistida sem sucesso contribui para o receio do fracasso na próxima tentativa. Parece-nos que o primeiro resultado negativo contribuiu para que, da segunda vez, Rebeca fosse mais consciente da possibilidade de insucesso.

Além de Rebeca, seu marido também não estava preparado para um resultado negativo. Interessante perceber que, assim como na história de Carla, apesar da grande dor que estava sentido, Rebeca precisou se fortalecer, deixando sua própria dor em segundo plano, para dar forças a seu esposo. Diante do insucesso, Rebeca e o marido encontram conforto na possibilidade de continuar tentando o tratamento, acreditando que, assim, ainda vão conseguir realizar o sonho da gravidez.

Chamou-nos atenção o fato de que, assim como Carla, Rebeca também fez o tratamento de fertilização em sigilo como forma de se proteger da cobrança familiar e social. Isso parece nos revelar a grande dificuldade de se ver como infértil. Vivenciar a impossibilidade de engravidar no momento em que deseja, fez com que Rebeca se sentisse diferente: “(...) Porque é como se a minha feminilidade, naquele momento, fosse extremamente questionada. Porque o feminino, o ser mulher deveria ser uma coisa que estivesse bem relacionada com o ser mãe". Tubert (1996) ressalta que a herança cultural continua transmitindo o dogma de que a maternidade é indispensável para a realização da feminilidade. Nesse sentindo, continua o autor, somos levados a acreditar que "Uma mulher não é verdadeiramente uma mulher se não tiver filhos” (p. 122). Interessante ressaltar que Rebeca já é mãe de três filhos, mas mesmo assim questiona sua feminilidade.

Rebeca acredita ter nascido com o dom da maternidade, uma vez que sua qualidade maternal está acima da qualidade enquanto profissional e esposa. Nas suas palavras: "Eu acho que é um dom. [...] Eu sei que eu sou uma boa profissional, eu sou uma boa esposa, mas eu sou muito mãe. [...] eu tenho um instinto materno muito aflorado". Tal fato parece corroborar com a fala de Makuch (2006), ao afirmar que, apesar do crescimento profissional, muitas mulheres continuam tendo na maternidade seu maior determinante de função social. Barbosa \& Rocha-Coutinho (2007) destacam que apesar de, atualmente, a mulher ser estimulada a ocupar o espaço público e valorizar a sua carreira profissional, o lugar da maternidade na nossa sociedade ainda é bastante valorizado.

Rebeca considera que a maternidade não é uma condição inerente a toda mulher: "O fato de ser mulher não quer dizer que seja mãe. [...] Elas são mulheres, mas não tem o menor instinto maternal”. Mais uma vez é interessante perceber que nossa narradora havia feito uma relação direta entre a maternidade e a feminilidade, contradizendo-se, a seguir. Na verdade, para Rebeca, parece haver uma certa confusão entre esta relação. Badinter (1985) também considera que o amor maternal não é instintivo ou biológico, mas sim construído socialmente, na relação diária da mãe com o filho. Possuindo a mesma linha de pensamento da autora, Rebeca considera que a maternidade está além do parto e do laço sanguíneo, pois a mulher pode ser mãe mesmo sem ter gerado o filho: "Então, eu acho que não dá para a gente associar: 'Eu sou mulher e sou mãe', porque, às vezes, você é mulher e você não é mãe. [...] Independe de você ter tido, de você ter parido, de você ter um laço sanguíneo. Você pode ser mãe mesmo sem você ter tido o filho.. Então, eu acho que a feminilidade é relacionada à maternidade. Porque você vai ter, vai gerar, tudo o que o homem não pode fazer. Mas, às vezes, a mulher não tem aquele instinto maternal". Desta forma, apesar de acreditar que a maternidade está ligada à feminilidade, uma vez que a experiência de gerar e parir um filho pertence única e exclusivamente ao universo feminino, Rebeca não considera que o instinto materno seja natural e inerente a todas as mulheres.

\subsection{A história de Amanda: ressignificando a materni- dade}

Após ter feito duas inseminações artificiais sem sucesso, Amanda, 42 anos, decidiu tentar o tratamento de fertilização in vitro. Teve muita dificuldade em decidir fazer o tratamento, pois além de não querer tomar hormônios, acreditava que a gravidez deveria ser uma benção divina. Entretanto, como o passar do tempo, foi per- 
cebendo que, no futuro, poderia se arrepender de não ter buscado ao máximo os recursos que a medicina oferecia. Decidiu parar com o tratamento, no entanto, após ter tido uma complicação de saúde na sua segunda fertilização. Atualmente, encontra-se num momento de indefinição, conforme nos fala a seguir: "Eu estou, no momento, sem tomar uma decisão definitiva porque, depois disso, pensei em adotar. Só que ainda não me veio aquela coragem, aquela força, aquele élan de tomar essa decisão".

Depois de ter vivenciado duas fertilizações sem sucesso, Amanda ficou sentindo a dor da frustração. Porém, apesar do sofrimento vivido, procura re-significar sua história para não ficar fixada na frustração e na dor da derrota: "Eu estou tentando não congelar aí nessa etapa, tentando vislumbrar uma alternativa como uma adoção, que é para não morrer aí essa história, numa frustração". Tal comportamento é muito comum em mulheres que se frustram com tentativas infrutíferas de engravidar. Oliveira (2006) defende que, diante do fim das tentativas de engravidar pela reprodução assistida, o casal infértil precisa se adaptar à frustração e criar novos objetivos e propostas de vida. A adoção é uma das opções mais buscadas.

Acreditando que a mulher precisa estar tranquila, decidida e determinada para ter sucesso no tratamento de fertilização, Amanda, finalmente, decidiu por não tentar a terceira vez. Podemos observar que, assim como na história de Carla e de Rebeca, Amanda incomoda-se com o sentimento de pena que as pessoas costumam sentir por mulheres e casais que não conseguem gerar um filho. De acordo com Barbosa \& Rocha-Coutinho (2007, p. 184), "[...] a mulher que não tem filhos ainda é vista como uma "coitada", uma "pessoa inferior", alguém que não conseguiu cumprir o seu principal papel”. Esse sentimento é muito semelhante ao que nossa colaboradora descreve: "O sentimento da infertilidade, em si, já é muito ruim, porque você, sem dúvida, acaba questionando o porquê da infertilidade. Você olha em volta e vê todas as suas amigas, as pessoas do seu convívio, todas essas pessoas com filhos e você sem filhos. Então, só daí, já dá uma inquietação. Então, por conta da infertilidade, já há um sentimento ruim, de ser diferente, de ser 'a' que não conseguiu ter filhos".

Durante o tratamento, Amanda entrou em contato com a questão da sua feminilidade, conforme ressalta: "Quando a gente começou a fazer os tratamentos veio à tona toda essa questão, também, da feminilidade, no sentido de que, para haver uma gravidez, a mulher precisa, realmente, estar com o seu feminino muito bem trabalhado. (...) Não tem como você querer ser mãe, sem estar muito bem consigo mesma no seu feminino".

Amanda ressalta que um ganho do tratamento foi a aproximação do casal, que acabou ficando mais cúmplice e companheiro. Já o lado doloroso foi vivenciado como uma sensação de mal-estar, angústia e autocompaixão. Contudo, apesar das dúvidas e do mal-estar, prevalecia a esperança de que a fertilização desse certo - sentimento que a motivava a continuar lutando. Oliveira (2006, p. 214) observou que "Ao longo do processo de fertilização assistida ocorrem perdas recorrentes e frustrações variadas, mas o otimismo e as esperanças sustentam o desejo pelo filho e os esforços necessários". Desta maneira, parece que é justamente essa esperança no resultado positivo que mantêm os casais na desgastante e angustiante luta do processo de fertilização in vitro.

Para Amanda, ser mulher é algo que traz o embelezamento da vida. Relata: "Ser mulher é uma dádiva, é uma benção, é algo do ponto do embelezamento da vida". Entretanto, em alguns momentos durante o tratamento, o problema da infertilidade fez com que Amanda se questionasse a respeito de sua feminilidade. Por considerar que a gravidez acontece naturalmente no ciclo de vida feminino, ela significa a infertilidade como algo estranho e inesperado, que desconfirma a condição feminina da mulher, conforme podemos observar no seguinte trecho: "Eu acho que teve momentos que esse sentimento de ser infértil me fez questionar o quanto eu era feminina (...) Esse fato de não gerar filhos vai de encontro ao que é natural. Porque, naturalmente, a mulher que tem relações sexuais, engravida. [...] O que acontece? Eu não sou mulher? Então, eu não sou mulher? Cadê o meu feminino? O meu homem, o meu marido espera de mim um filho. E cadê? Como é que fica isso (...) Nossa! Nasci como mulher e não consigo uma coisa que é mais inerente da mulher, que é gerar filhos, amamentar, parir, ser mãe e maternar!” [...] Eu não passei por isso, eu não tive êxito em ser mulher!".

Amanda não quer que a ideia de adoção seja apenas uma solução para preencher o vazio que ficou depois da sua frustração com a fertilização in vitro. Tem razão no seu cuidado. Zibini \& Vasconcellos (2006), por exemplo, ressaltam que a adoção não pode ser pautada na busca de resolução para uma história de insucessos, pois ela não apaga a marca da infertilidade. Ao contrário, muitas vezes, pode ser sua prova viva. Desta forma, os lutos não elaborados podem interferir negativamente na relação com o filho adotado.

Amanda acredita que o amor materno vem do coração, e não da barriga, sendo construído no convívio diário a partir do contato. Amplia sua representação da maternidade, defendendo que ela não começa, necessariamente, com uma gravidez, pois acredita que a mulher começa a ser mãe a partir do ponto em que opta por isso, em qualquer momento da sua vida. Em seus estudos a respeito do vínculo afetivo entre mãe e filho, Badinter (1985) chegou à conclusão que o amor materno é resultado de uma construção sociocultural, não tendo relação com instinto, fator sanguíneo ou determinismo da natureza.

Contudo, apesar de Amanda ser simpatizante da adoção, ela ainda não pode se decidir por adotar uma criança, acreditando que: “(...) esse amor que se tem aos filhos é muito construído no dia-a-dia, no convívio, no olhar, no sentir mesmo. Eu acho que não vem da barriga". 


\subsection{A história de Joana: a concretização do sonho}

Após ter sofrido dois abortos, Joana tentou mais de um tipo de tratamento para conseguir engravidar naturalmente e sustentar o bebê. Entretanto, depois de mais de um ano de tentativas sem sucesso, decidiu partir para a fertilização in vitro. Narrou a experiência de tomar as injeções de hormônio como algo muito desagradável, doloroso e desconfortável. Outro momento de muita ansiedade e medo foi o procedimento de retirada dos óvulos. Durante vários momentos da entrevista, Joana ressaltou que o tratamento de fertilização exige muita determinação e perseverança. Além do desejo de ser mãe, o que motivou Joana a persistir no tratamento foi a vontade de formar uma família, pois considera que ela e o marido formam apenas um casal. Farinati, Rigoni \& Müller (2006) observaram que muitos casais se unem motivados pelo alto valor colocado na constituição de uma família. A respeito desse desejo de constituir uma família, Oliveira (2006) esclarece que:

A própria relação amorosa, que resulta na união de um casal, traz consigo o desejo de crescer e aumentar os vínculos e as responsabilidades compartilhadas - e uma das formas é através de uma criança. Esse desejo é parte da construção de um casal, um projeto de família e de futuro, representação da continuidade do casal e da família maior, como herança de sua história e de seus valores (p. 209).

Em meio à sua dificuldade de ter um filho, quando Joana pensava em adoção, rejeitava a ideia, pois ficava com medo do filho adotivo querer procurar a família biológica quando crescer e acabar gostando mais dos pais biológicos do que dela e do seu marido. Segundo Carvalho, Seibel, Makuch \& Maluf (2006b), "Um medo comum é a necessidade de um relacionamento de sangue, para que possa existir uma relação intensa. Outro medo comum, é que a criança adotada, em algum momento, venha rejeitar os pais adotivos, dando preferência aos pais biológicos" (p. 34). Então, o medo de Joana parece ser comum em mulheres com vivência semelhante a dela.

Assim como as outras participantes, Joana colocou que se sentia diferente das outras mulheres, por vivenciar a dificuldade de engravidar e a impossibilidade de segurar uma gravidez. Podemos observar o quanto essa experiência foi sofrida, no seguinte relato: "Quando você não consegue se reproduzir, ou nos primeiros meses, quando eu perdi a primeira gravidez, para mim, foi a pior coisa do mundo. Era como se eu fosse diferente [...] mas eu me perguntei, dentro de mim: "O que foi que aconteceu?"

No que diz respeito à questão da feminilidade, parece-nos que Joana associa o fato de ser mulher à capacidade hormonal de poder gerar um filho naturalmen- te. Apesar de também falar que para uma mulher ser feminina, ela precisa se arrumar e cuidar da sua beleza, Joana destaca a qualidade hormonal como principal fator da feminilidade: "Precisa ter os hormônios funcionando bem", afirma.

Mondelli \& Levy (2006) destacam que o discurso hegemônico da maternidade cria a ideia de que é natural uma mulher ser mãe. Segundo essas autoras, "a impossibilidade de tal situação põe por terra a condição de mulher. Esta já não mais se reconhece, pois é a partir da gravidez, o viver o que a natureza lhe reservou, que a possibilidade de completude se dá" (p. 53). Nesse sentido, podemos perceber o quanto a ideia de feminilidade está, culturalmente, associada à capacidade da mulher gerar um filho. Joana, assim como afirmam os autores, considera que ser mulher é ser capaz de reproduzir, gerar um filho.

Joana considera a maternidade uma grande responsabilidade e, ao mesmo tempo, um grande prazer. Enfatiza que deseja passar o máximo de tempo que puder com o seu filho, pois considera que o contato afetivo materno é insubstituível: "[...] eu queria, toda hora extra, estar sempre em contato, para que ele tenha referência sempre em mim, próxima de mim, que sou mãe dele [...] o contato afetivo materno, a maternidade, pra mim, é insubstituível. [...]Então, eu vejo a maternidade assim, tem que fazer essa referência desde o nascimento do nenê".

Interessante observar, no seguinte trecho, as representações que Joana possui do filho biológico: " $\mathrm{Eu}$ vou receber uma nova pessoa da família, um novo descendente. Eu até brinquei com ele hoje, eu disse: "Eu vou ter um rapaz. Se Deus quiser, na velhice, quando eu tiver idosazinha, vai me fazer muita companhia!". Parecenos que, além da continuação da família, que se estende e prospera com a vinda de um descendente, o filho biológico significa, para ela, o fim da solidão parental, uma vez que ele faria companhia aos pais durante a velhice. Trindade \& Enumo (2002) já haviam observado que algumas mulheres relatam a necessidade de terem um filho para não ficarem sozinhas. Além disso, Borlot e Trintade (2004) constataram que a questão da descendência é uma das fortes representações sociais em relação ao filho biológico.

\section{Considerações Finais}

Ao longo do trabalho, foi possível perceber como a incapacidade de gerar um filho naturalmente é sentida como uma experiência dilaceradora para essas mulheres. Tal fato faz com que elas se considerem incapazes, inúteis e "danificadas", pois sentem que falharam em uma função característica do feminino, isto é, conceber, gestar e parir um filho.

A fala das colaboradoras dessa pesquisa deixa perceber que a visão idealizada da maternidade como algo sublime e como condição para que a mulher se sinta 
completa e realizada, continua presente no discurso da sociedade atual. Além disso, podemos perceber o quanto a maternidade ainda é associada à feminilidade, uma vez que a impossibilidade de gerar um filho é significada como uma desqualificação na característica de ser feminina. Nesse sentido, as experiências relatadas nesta pesquisa sustentam a representação social de que o fato de ser mãe afirma a feminilidade e assegura a condição de ser mulher.

Tendo em vista a própria condição de devir inerente ao ser humano, temos a clareza de que os resultados desta pesquisa representam apenas o início de uma compreensão que não se esgota. O complexo fenômeno da infertilidade e suas decorrentes implicações na vida e subjetividade daqueles que vivenciam essa questão ainda oferecem muito a ser feito, pensado e indagado sobre o tema.

\section{Referências}

Badinter, E. (1985) Um amor conquistado: o mito do amor materno. Rio de Janeiro: Nova Fronteira.

Barbosa, P. Z. \& Rocha-Coutinho, M. L. (2009). Maternidade: novas possibilidades, antigas visões. Psicologia Clínica (Rio de Janeiro), 19(1), 163-185.

Borlot, A. M. M. \& Trindade, Z. A. (2004). As tecnologias de reprodução assistida e as representações sociais de filho biológico. Estudos de Psicologia (Natal), 9(1), 63-90.

Borsa, J. C. \& Feil, C. F. (2008). O papel da mulher no contexto familiar: uma breve reflexão. [online]. Disponível em: <http://www.psicologia.com.pt/artigos/textos/A0419.pdf>. Acesso em: 11 dez. 2008.

Braga, M. da G. R. \& Amazonas, M. C. L. de A. (2005). Família: maternidade e procriação assistida. Psicologia em Estudo (Maringá), 10(1), 11-18.

Carvalho, C. A. P.; Seibel, D.; Makuch, M. Y. \& Maluf, V. D. (2006, a). Guia sobre saúde mental em reprodução humana. Atualização 2006 [online]. Comitê de Psicologia da SBRH. Disponível em: http://www.sbrh.org.br/sbrh_novo/guidelines/guideline_pdf/guideline_de_psicologia.pdf

Carvalho, C. A. P.; Seibel, D.; Makuch, M. Y. \& Maluf, V. D. (2006, b). Estresse na reprodução assistida. Arquivos H. Ellis: Saúde Sexual e Reprodutiva, 2(4). Disponível em: <http://www. arquivoshellis.com.br/revista/02_040606/02_040606_ ahellis_01.pdf>. Acesso em: 15 nov. 2008.

Cunha, A. C. R.; Wanderley, M. S. \& Garrafa, V. (2007). Fatores associados ao futuro reprodutivo de mulheres desejosas de gestação após ligadura tubária. Revista Brasileira de Ginecologia e Obstetrícia (Rio de Janeiro), 29(5), 230-234.

Dutra, E. (2002). A narrativa como uma técnica de pesquisa fenomenológica. Estudos de Psicologia (Natal), 7(2), 113-121.

Farinati, D. M.; Rigoni, M. dos S. \& Müller, M. C. (2006). Infertilidade: um novo campo da Psicologia da saúde. Estudos de Psicologia, (Campinas), 23(4), 433-439.
Frota, A. M. M. C. (2001). O desalojamento e a reinstalação do si-mesmo: um percurso fenomenológico para uma compreensão da adolescência, a partir de narrativas. Tese Doutorado. Instituto de Psicologia, Universidade de São Paulo, São Paulo.

Holanda, A. (2001). Pesquisa Fenomenológica e Psicologia Eidética: elementos para um entendimento metodológico. Em A. F. Holanda \& M. A. T. Bruns (Orgs.), Psicologia e Pesquisa fenomenológica: reflexões e perspectivas. São Paulo: Ômega Editora.

Melo, S. M. (2012). A Saga de Hefesto: hermenêutica colaborativacomo possibilidade de ação humanista-fenomenológica em clinica de trabalho. Tese de Doutorado. Programa de Pós-Graduação em Psicologia Clinica da Universidade Católica de Pernambuco.

Makuch, M. Y. (2006). Gênero e reprodução assistida: novas fases e velhas questões. In: R. M. Melamed \& J. Quayle (Orgs.). Psicologia em reprodução assistida: experiências brasileiras (p. 21-33). São Paulo: Casa do Psicólogo.

Melamed, R. M. M. (2006). Infertilidade: sentimentos que decorrem. In: R. M. M. Melamed \& J. Quayle (Orgs.). Psicologia em reprodução assistida: experiências brasileiras (p. 71-90). São Paulo: Casa do Psicólogo.

Melamed, R. M. M.; Ribeiro, M. F. da R. \& Seger-Jacob, L. (2006). O casal infértil e o profissional de saúde mental - possíveis abordagens. In: R. M. Melamed \& J. Quayle (Orgs.). Psicologia em reprodução assistida: experiências brasileiras (p. 167-188). São Paulo: Casa do Psicólogo.

Modelli, A. \& Levy, R. H. C. (2006). Esterilidade sem causa aparente: possibilidades de intervenção. In: R. M. Melamed \& J. Quayle (Orgs.). Psicologia em reprodução assistida: experiências brasileiras (p. 49-69). São Paulo: Casa do Psicólogo.

Oliveira, C.C. (2006). O luto pela criança que não nasceu. In: R. M. Melamed \& J. Quayle (Orgs.). Psicologia em reprodução assistida: experiências brasileiras (p. 207-220). São Paulo: Casa do Psicólogo.

Pinheiro, S. L. (2007). Uma Compreensão da Infância dos Índios Jenipapo-Kanindé a partir de Narrativas. Trabalho de Conclusão de Curso, Graduação em Psicologia, Universidade Federal do Ceará, Fortaleza.

Ribeiro, M. (2006). Articulações entre narcisismo e reprodução assistida. In: R. M. Melamed \& J. Quayle (Orgs.). Psicologia em reprodução assistida: experiências brasileiras (p. 91-103). São Paulo: Casa do Psicólogo.

Rocha-Coutinho, M. L. (1994). Tecendo por trás dos panos: a mulher brasileira nas relações familiares. Rio de Janeiro: Rocco.

Rogers, C. \& Kinget, M. G. (1969/1975) Psicoterapia e Relações Humanas. Belo Horizonte: Interlivros.

Seger-Jacob, L. (2006). Estresse na gênese e no tratamento da infertilidade. In: R. M. Melamed \& J. Quayle (Orgs.). Psicologia em reprodução assistida: experiências brasileiras (p. 121-153). São Paulo: Casa do Psicólogo. 
Trindade, Z. A. \& Enumo, S. R. F. (2002). Triste e Incompleta: Uma Visão Feminina da Mulher Infértil. Psicologia USP (São Paulo), 13(2), 151-182.

Tubert, S. (1996). Mulheres sem sombra: maternidade e novas tecnologias reprodutivas. Rio de Janeiro: Record: Rosa dos Tempos.

Weiss, T. K. (2006). O impacto da infertilidade e seu tratamento nos casais. In: R. M. Melamed \& J. Quayle (Orgs.). Psicologia em reprodução assistida: experiências brasileiras (p. 105-119). São Paulo: Casa do Psicólogo.

Zibini, M. V. C. \& Vasconcellos, C. B. (2006). Infertilidade e adoção: algumas reflexões. In: R. M. Melamed \& J. Quayle (Orgs.). Psicologia em reprodução assistida: experiências brasileiras (p. 243-259). São Paulo: Casa do Psicólogo.

Renata Ramalho Queiroz Leite - Graduada em Psicologia pela Universidade Federal do Ceará (UFC), e Analista Judiciário, com Especialidade Psicologia do Tribunal Regional Eleitoral do Ceará (TRE-CE). E-mail: renatarq@hotmail.com

Ana Maria Monte Coelho Frota - Graduada em Psicologia e Mestre em Educação pela Universidade Federal do Ceará (UFC), com Doutorado em Psicologia Escolar e do Desenvolvimento Humano pela Universidade de São Paulo (USP). Atualmente é Professora Associada do Departamento de Economia Doméstica da Universidade Federal do Ceará (UFC). Vinculada ao Programa de Pós-graduação em Educação Brasileira da Universidade Federal do Ceará. Endereço Institucional: Universidade Federal do Ceará, Centro de Ciências Agrárias, Departamento de Economia Doméstica. Avenida Mister Hull. 60356000. Fortaleza, Ceará. E-mail: anafrota@ufc.br

Recebido em 13.08.13 Primeira Decisão Editorial em 08.01.14 Aceito em 24.04.14 